\title{
Complete cycles of bloodstream trypanosome RNA editing in vitro
}

\author{
KARI HALBIG, ${ }^{1}$ MONICA DE NOVA-OCAMPO, ${ }^{1}$ and JORGE CRUZ-REYES \\ Department of Biochemistry and Biophyisics, Texas A\&M University, College Station, Texas 77843, USA
}

\begin{abstract}
RNA editing in kinetoplastid protists is required for the maturation of mitochondrial pre-mRNAs and occurs by proteincatalyzed cycles of uridylate insertion and deletion. During the complex life cycle of Trypanosoma brucei this process is differentially regulated in the mammalian bloodstream and insect procyclic stages. Complementary guide RNAs (gRNAs) direct editing, but the abundance of these transcripts is not developmentally controlled. The establishment of in vitro systems that recreate efficient RNA editing in bloodstream $T$. brucei would be valuable for mechanistic studies of regulation. Here we describe a robust in vitro system that reconstitutes full cycles of both $U$ insertion and $U$ deletion in bloodstream trypanosomes, and the first direct comparisons of the in vitro systems for strains of mammalian and insect stages.
\end{abstract}

Keywords: Trypanosoma brucei; RNA editing; bloodstream form

\section{INTRODUCTION}

RNA editing by uridylate insertion and deletion in the single mitochondrion of early-branched kinetoplastid protozoa is a posttranscriptional mRNA maturation process (for reviews, see Madison-Antenucci et al. 2002; Stuart and Panigrahi 2002; Simpson et al. 2004). All pre-edited mRNA (pre-mRNA) substrates and small trans-acting guide RNAs (gRNAs) directing the editing are encoded in the mitochondrial DNA network known as the kinetoplast (Blum et al. 1990; Lukes et al. 2002). In Trypanosoma brucei, this editing remodels 1362 phosphodiester bonds within 12 of the 18 mRNAs encoded in the mitochondrial genome (Burguess and Stuart 2000).

T. brucei undergoes a complex life cycle involving dramatic stage-specific adaptative changes to survive in the vector tsetse fly and mammalian hosts, some of which affect mitochondrial biogenesis (Vickerman 1985; Priest and Hajduk 1994; Gull 2001). The dividing insect procyclic (Pf) and mammalian bloodstream slender (Bf) forms employ different sources of ATP. While Pf cells contain fully developed mitochondria and a functional respiratory chain, Bf cells produce ATP largely by glycolysis. In the latter, mito-

\footnotetext{
${ }^{1}$ These authors contributed equally to this work.

Reprint requests to: Jorge Cruz-Reyes, Department of Biochemistry and Biophyisics, Texas A\&M University, 2128 TAMU, College Station, TX 77843, USA; e-mail: cruzrey@tamu.edu; fax: (979) 862-4718.

Article and publication are at http://www.rnajournal.org/cgi/doi/ 10.1261/rna.5157704.
}

chondria are functionally repressed as they lack cytochromes and Krebs enzymes, and are much reduced in size (Vickerman 1985; Priest and Hajduk 1994). This switch in ATP source appears controlled, at least in part, by differential RNA editing (Stuart et al. 1997), but may also involve changes in RNA activation/inactivation, turnover, and translation ability. The latter may include differential cleavage of polycistronic mRNA precursors (Koslowsky and Yahampath 1997) and controlled accumulation of rRNA and polyadenylylated mRNA transcripts that are edited, preedited, or never edited (Bhat et al. 1992; Michelotti et al. 1992; Read et al. 1994; Militello and Read 1999). Editing can be stage specific or constitutive, as is the case for apocytochrome b and ATPase 6 pre-mRNAs, respectively (Stuart et al. 1997). Yet the molecular basis of this developmental control is unknown. Although the steady-state levels of several edited mRNAs vary significantly between Pf and Bf mitochondria, the abundance of gRNA species is similar and unlikely to control editing. However, differential gRNA usage has not been ruled out (Stuart et al. 1997; Pelletier and Read 2003). Editing is essential for survival of both developmental forms, yet its precise role in Bf trypanosomes is not known (Rusché et al. 2001; Schnaufer et al. 2001). A complete cycle of Pf gRNA-directed editing was reproduced in vitro by Seiwert and Stuart (1994). In vitro editing has also been established in the related Leishmania system (Byrne et al. 1996; Pai et al. 2003). An editing cycle involves pre-mRNA endonuclease cleavage, $\mathrm{U}$ addition or $\mathrm{U}$ removal, and RNA ligation (Cruz-Reyes and Sollner-Webb 
1996; Kable et al. 1996; Seiwert et al. 1996). Furthermore, Pf deletion and insertion in a common complex may be differently regulated as the two processes involve separate activities and enzymes (Cruz-Reyes et al. 1998a,b, 2002; Huang et al. 2001). In fact, partial-deletion or partial-insertion editing can be catalyzed by separate subcomplexes (Stuart and Panigrahi 2002; Schnaufer et al. 2003). The physical partition of the two kinds of editing may also occur for the similar Leishmania editing complex (Simpson et al. 2004). Pf insertion and deletion also exhibit different RNA requirements (Cruz-Reyes et al. 2001; Igo et al. 2002a,b). In vitro systems for $\mathrm{Bf}$ trypanosomes are needed to address the molecular mechanism of RNA editing regulation. Partial editing of precleaved substrates has been detected in $\mathrm{Bf}$ form trypanosomes (Domingo et al. 2003) but no systematic studies comparing in vitro editing in the two trypanosome forms have been reported. Here we report a robust in vitro system that faithfully recreates complete cycles of both insertion and deletion in $\mathrm{Bf} T$. brucei. Our initial direct comparisons of $\mathrm{Pf}$ and $\mathrm{Bf}$ editing in vitro reveal significant similarities in apparent assembly of catalytic complexes. Furthermore, although the ATP requirements for insertion catalyzed by $\sim 20 \mathrm{~S}$ editing complexes differed significantly between the tested strains, they appeared relatively conserved for deletion.

\section{RESULTS AND DISCUSSION}

We sought to establish full cycles of Bf RNA editing of sufficient efficiency to begin comparative studies with the well-established Pf in vitro system. To this end, we obtained high densities of human nonpathogenic T. brucei brucei subspecies from infected rats $\left(\sim 10^{9}\right.$ cells $/ \mathrm{mL}$ of blood). Parasites were separated from blood components, and RNA editing activity was assayed in soluble mitochondrial extracts under conditions similar to those used to assay Pf editing (Cruz-Reyes et al. 2001). We detected accurate U deletion and $\mathrm{U}$ insertion at editing site 1 (ES1) and ES2, respectively, of the constitutively edited ATPase subunit 6 (A6) pre-mRNA (Fig. 1A,B, lanes 1). The correct gRNAdirected number of removed or added uridylates at these sites was confirmed by RNase sequencing of eluted products (data not shown; as in Cruz-Reyes et al. 1998b). Similarly to the Pf system, both accurate and partial Bf editing depends on exogenously added gRNA, and $\mathrm{U}$ insertion also depends on exogenous UTP (Fig. 1A,B, lanes 1-3; Kable et al. 1996). To show that potential endogenous phosphatase activity in the extract does not generate artifactual slow-moving bands (by removing terminal $5^{\prime}$ tri-phosphate and $3^{\prime}$ phosphate of the synthetic $3^{\prime}$-labeled substrate), the reaction was stopped after editing and the RNA treated with alkaline phosphatase prior to gel separation. Treated and untreated control reactions were compared. Although the former showed the expected decreased RNA mobility, the general banding pattern remained unchanged in the two samples (Fig. 1B, lanes

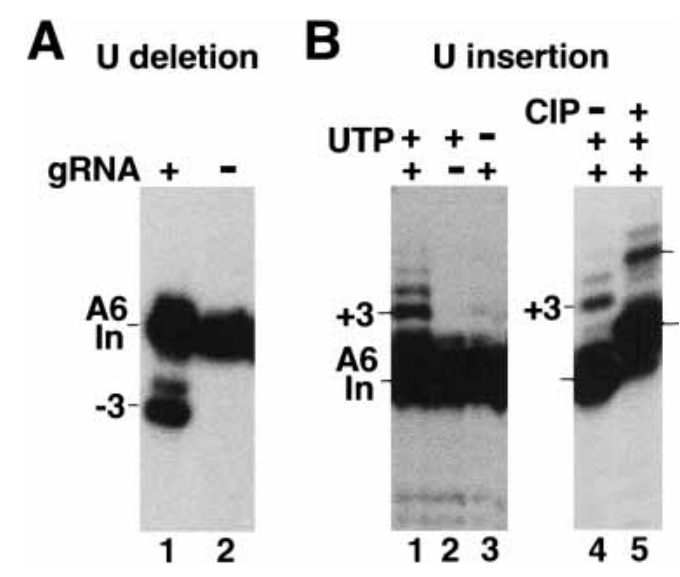

FIGURE 1. Complete cycles of Bf RNA editing. A6 deletion and insertion cycles in Bf crude mitochondrial extracts using $3^{\prime}$-end-labeled pre-mRNA and enhanced gRNAs. $(A)$ Deletion reaction with and without gRNA. $(B)$ Insertion reaction with gRNA and UTP or without either gRNA or UTP (lanes 1-3). Upon editing reaction completion and deproteinization, the RNA transcript was treated or not with calf intestinal alkaline phosphatase (CIP) and loaded (lanes 4 and 5, respectively). The phosphatase treatment removes all $5^{\prime}$ tri- and $3^{\prime}$ mono-phosphates in $3^{\prime}$-end-labeled RNA transcripts, thereby significantly slowing down their gel mobility. Accurate deletion and insertion products are indicated as -3 and +3 , respectively. Partially edited products are also detected. (A6 in) Input A6 pre-mRNA.

4,5). This result confirms that the slow-moving bands are largely generated by editing, with no significant contribution by potential phosphatases in the Bf crude mitochondrial extract.

To characterize the $\mathrm{Bf}$ insertion and deletion activities, we subjected $\mathrm{Bf}$ and Pf crude mitochondrial extracts to parallel sedimentation gradients and assayed each fraction for A6 insertion, A6 deletion, and self-adenylylation (of RNA ligase) activities. The distribution of these activities in the gradients suggests the presence of large Bf editing complexes as in procyclics (Fig. 2A,B; data not shown). Complexes capable of insertion and deletion and associated ligases in the $\mathrm{Bf}$ and $\mathrm{Pf}$ extracts exhibit a similar peak near the 19S marker (Fig. 2; Corell et al. 1996; Cruz-Reyes and Sollner-Webb 1996; Rusché et al. 1997; Cruz-Reyes et al. 1998b). However, although very similar, the distribution of $\mathrm{Bf}$ and $\mathrm{Pf}$ complexes is not identical. The peak of insertion activity in the Bf cells appears slightly more spread toward the $15 \mathrm{~S}$ region than in the Pf cells (e.g., compare fractions 9-12 in both gradients, upper panels). The distribution patterns of insertion activity with a given life cycle stage are confirmed by nearly identical patterns of deletion activity (Fig. 2A,B, middle panels). The profile of RNA ligase adenylylation is less indicative of the position of functional editing complexes (Fig. 2A,B, lower panels). In Pf mitochondrial extracts, some ligase activity can be found dissociated from catalytic editing complexes (Schnaufer et al. 2003). The Bf sedimentation profile is not affected by potential presence of rat serum components in our preparations (e.g., proteases or proteins binding to the RNA sub- 


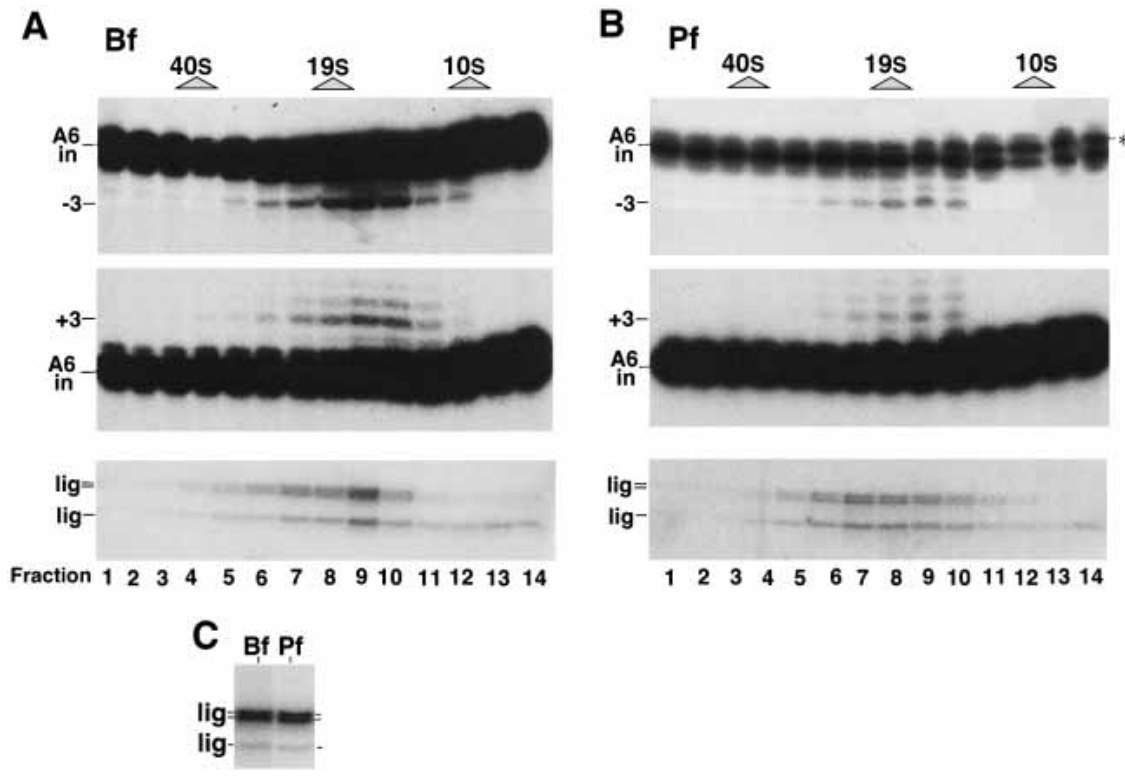

FIGURE 2. Isopycnic centrifugation of $\mathrm{Bf}$ and $\mathrm{Pf}$ editing activities. Crude mitochondrial extracts $(0.5 \mathrm{~mL}$ at $\sim 2 \mathrm{mg} / \mathrm{mL}$ ) from strains (Bf) ILTat1.3 and (Pf) TREU667 were fractionated in glycerol gradients and each fraction assayed for full cycles of A6 deletion and insertion, and adenylylation activities (top, middle, and bottom panels, respectively). $\mathrm{Bf}(A)$ and $\mathrm{Pf}(B)$ editing activities. Some sedimentation fractions generate $\mathrm{a}+1$ band $\left({ }^{*}\right)$ not related to editing (see text). The Pf ligases most commonly termed REL1 and REL2, or Bands IV and V, respectively (Rusché et al. 1997; Schnaufer et al. 2001; Simpson et al. 2004; see also McManus et al. 2000), and corresponding Bf adenylylated proteins (with $\left[\alpha-{ }^{32} \mathrm{P}\right]$-ATP as in Sabatini and Hajduk $1995)$ are indicated as "lig". Fraction one is at the bottom of the gradient. (C) The adenylylated $\mathrm{Pf}$ and Bf ligases, run side by side, exhibit the same gel mobility. Two isoforms (doublet) of the larger ligase (Rusché et al. 1997) are also present in the strain Bf ILTat1.3.

strate). We determined this by transferring Pf cells into rat whole blood before harvesting the trypanosome mitochondria (see Materials and Methods; data not shown). Both Bf and Pf gradients exhibit a major +1 RNA mostly in low sedimentation fractions (e.g., see Fig. 2B, upper panel; data not shown). Such activity does not require gRNA, UTP, nor ATP, and does not affect the sequence of the targeted editing region (as determined by RNase sequencing; data not shown). Thus, the responsible activity is most likely unrelated to the editing process studied. The adenylylated ligases in procyclics and bloodstream forms show similar gel mobility and most likely correspond to the same proteins (Fig. 2C).

The data above was obtained using two common laboratory strains (Bf) ILTat1.3 and (Pf) TREU667. To distinguish between potential strain-specific and stage-specific differences we performed parallel sedimentation analysis of the T. brucei strain 427 that can be grown in both stages (Wirtz et al. 1998). Consistent with the observations above, the distribution of functional complexes is similar but not identical between the two forms of 427 cells (Fig. 3A,B). Spe-

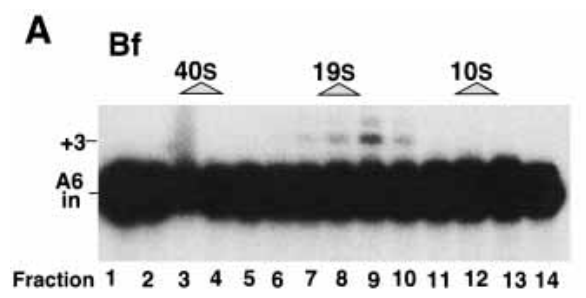

cifically, the peak of editing activity in the Bf system sediments slightly closer to the $\sim 15 \mathrm{~S}$ region than in the $\mathrm{Pf}$ system (e.g., compare the distribution of editing activity in fractions $8-10$ of both gradients). Interestingly, apparent strain-specific differences are also observed. For instance, the editing profiles in both forms of 427 cells are detected in less fractions (Fig. 3), particularly above $\sim 20$, than the corresponding ILTat 1.3 and TREU667 profiles (Fig. 2).

Together, these sedimentation analyses suggest that $\mathrm{Bf}$ and $\mathrm{Pf}$ editing complexes are very similar but not identical. These results were consistently observed in parallel sedimentation gradients of independently prepared mitochondrial extracts from these strains (data not shown). Potential structural differences in Bf and Pf complexes may have important functional implications. Interestingly, deletion and insertion activities, and associated functional proteins, appear partitioned in a common Pf complex (Cruz-Reyes et al. 1998a,b, 2002; Huang et al. 2001; Stuart and Panigrahi 2002; Schnaufer et al 2003). This is most likely also the case in Bf complexes.

Previous reports using ion-exchange-chromatographypurified Pf editing complexes from strain TREU667 showed that A6 deletion and insertion exhibit different ATP requirements (Cruz-Reyes et al. 1998a,b, 2002). We compared peak editing fractions (at $\sim 20 \mathrm{~S}$ ) of Bf and Pf strains in ATP titrations. Similar deletion profiles were observed in all $\mathrm{Bf}$ and $\mathrm{Pf}$ strains tested (Figs. 4A, 5A, upper panels). That is, deletion editing was relatively efficient between 3 and 0.03 mM ATP (lanes 1-3) but quite inefficient with $0.003 \mathrm{mM}$ and no added ATP (lanes 4,5). Interestingly, deletion in Bf 427 cells is maximal at $0.3 \mathrm{mM}$ rather than at $3 \mathrm{mM}$ as in the other deletion profiles. In surprising contrast, the insertion profile is similar between Bf strains but different

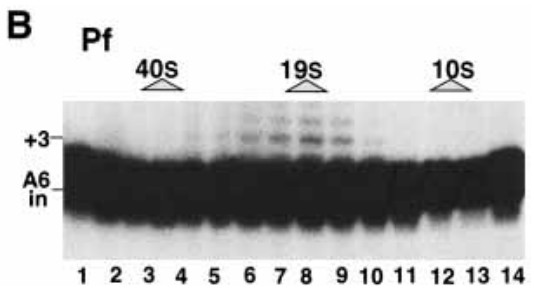

FIGURE 3. Isopycnic centrifugation of $\mathrm{Bf}(A)$ and $\mathrm{Pf}(B)$ editing activities. Crude mitochondrial extracts $(0.5 \mathrm{~mL}$ at $\sim 2 \mathrm{mg} / \mathrm{mL})$ from Bf (90.13) and Pf (29.14) cell lines of the strain 427 were fractionated in glycerol gradients and each fraction assayed for full cycles of A6 insertion. 
A

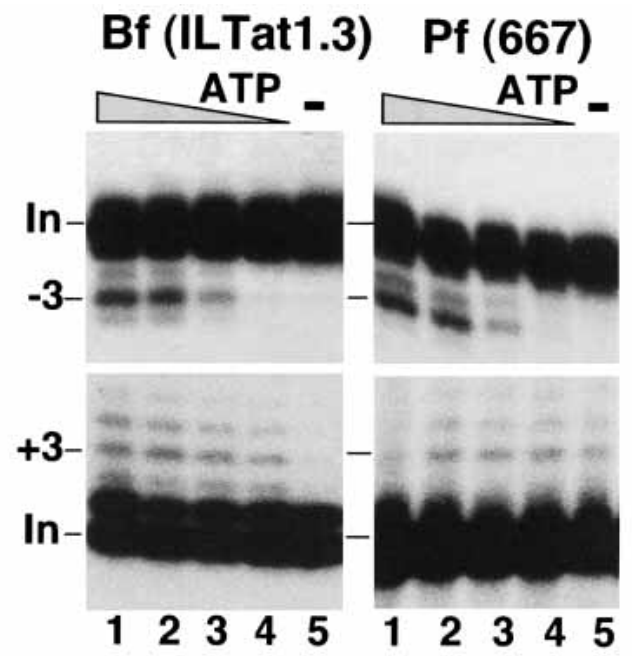

B

Deletion

Insertion
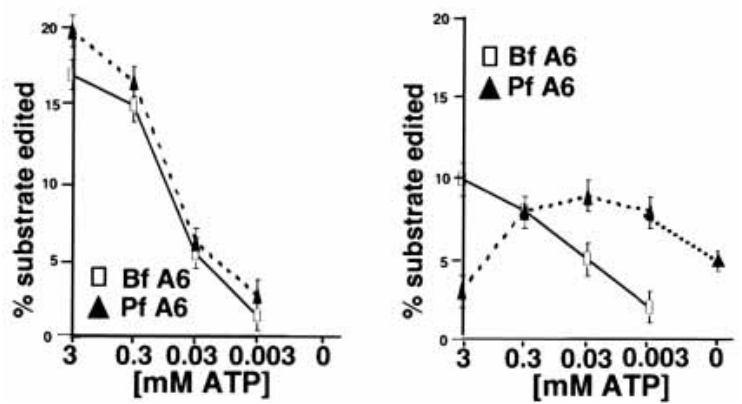

FIGURE 4. ATP titrations of $\mathrm{Pf}$ and $\mathrm{Bf}$ full editing cycles of $\mathrm{A} 6$ pre-mRNA in $\sim 20 S$ fractions. (A) Bf ILTat1.3 and Pf TREU667 editing reactions (left and right panels, respectively). (-3) Accurate A6 deletion products (top panels). $(+3)$ Accurate A6 insertion products (bottom panels). Lanes 1-5 contain 3, 0.3, 0.03, $0.003 \mathrm{mM}$, and no ATP, respectively. (B) Percent of substrate accurately edited at decreasing ATP concentrations. Empty and filled symbols denote Bf and Pf reactions, respectively. Conditions not supporting visible editing are not represented in the plots. ATP concentrations higher than $3 \mathrm{mM}$ (up to $4 \mathrm{mM}$ ) had no additional effect (not shown). The percent of accurate editing ( -3 and +3 bands for deletion and insertion, respectively) at different ATP concentrations relative to the remaining input (In) was quantitated with a PhosphorImager. Some fractions generate a prominent +1 RNA band, which is not a product of editing (see text and Fig. 2 legend) and remained constant throughout the ATP titration. Each point in the plots represents the average of duplicate ATP titrations performed simultaneously, with standard deviations (a single experiment). The data is representative of at least two independent experiments.

between Pf strains. Namely, in both Bf strain cells (ILTat1.3 and 427) insertion is maximal at $3 \mathrm{mM} \mathrm{ATP}$, and undetectable with no added ATP (Figs. 4A and 5A, lower left panels), whereas in strain (Pf) TREU667 insertion is partially depressed with either $3 \mathrm{mM}$ or no added ATP but maximal between 0.3 and $0.003 \mathrm{mM}$ ATP, and in strain (Pf) 427 insertion has maximal activity at $3 \mathrm{mM}$ but largely reduced activity between 0.3 and $0.003 \mathrm{mM}$ and with no added ATP.
Although additional work is needed to account for these insertion differences between strains, it is possible that different amounts of precharged ligase within the extracts may influence the levels of insertion, particularly between 0 and 3 nM ATP, because the editing ligases can be fully charged at $\sim 6$ nM ATP (Cruz-Reyes et al. 2002). Much higher ATP levels (millimolar range) affect editing at mRNA cleavage in TREU667 (Cruz-Reyes et al. 1998a,b) and most likely also in other strains. It is conceivable that different ATP requirements for insertion, particularly at $\mathrm{mM}$ range, reflect potential functional differences in the editing machinery between strains and even between the two stages. Further studies in our laboratory will further address this possibility. The plots in Figures $4 \mathrm{~B}$ and 5B depict absolute editing activity for those particular titrations. It should be emphasized that independent extract preparations vary in absolute editing activity, yet the relative changes of activity upon ATP titration are reproducible between preparations, and the plotted data is representative (data not shown).
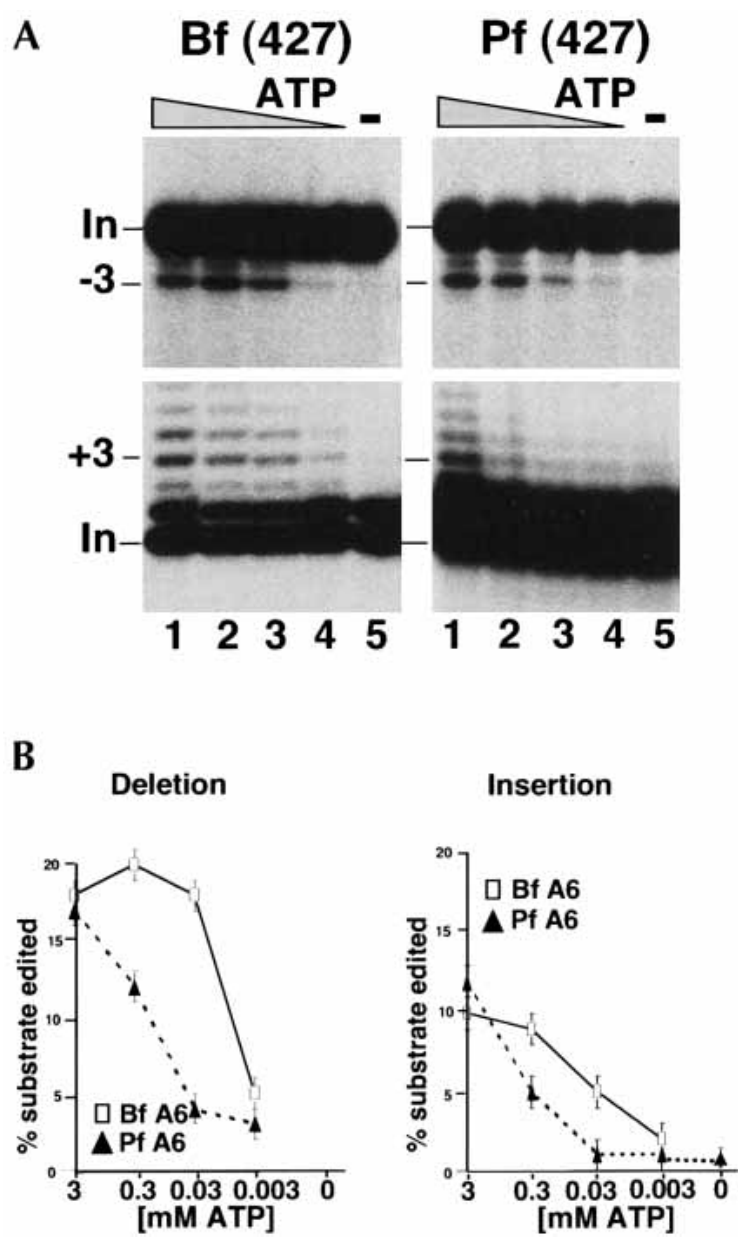

FIGURE 5. ATP titrations of $\mathrm{Pf}$ and $\mathrm{Bf}$ full editing cycles of $\mathrm{A} 6$ pre-mRNA in $\sim 20$ S fractions. (A) Bf and Pf cell lines of the strain 427 (left and right panels, respectively). (B) Percent of substrate accurately edited at decreasing ATP concentrations. The titrations and analyses were performed as in Figure 4. 
The $\sim 20$ S editing activities may be affected by potential levels of endogenous phosphatases (through ATP hydrolysis) and/or ATP in the sedimentation fractions; however, several observations suggest the above profiles are representative of relative deletion and insertion efficiencies for the tested strains. First, the ATP dependence for A6 deletion is more similar than insertion between the Bf and Pf strains tested (Figs. 4, 5). Second, the particular ATP dependence of A6 deletion and insertion in $20 \mathrm{~S}$ fractions of the Pf strain TREU667 was also observed with ion-exchange purified editing complexes of the same strain (Cruz-Reyes et al. 1998a). Finally, the gel mobility of the input pre-mRNA remained the same before and after the editing reactions (not shown). This suggests the absence of significant levels of endogenous phosphatase activity that could hydrolyze ATP. Such activity could be detected by its potential to remove the RNA transcript terminal phosphates and thereby change its gel mobility. An example of this was shown with a sample treated with alkaline phosphatase (Fig. 1B). Together, these data suggest that full cycle editing for Bf and Pf trypanosomes can be systematically compared in vitro. We also show that significant differences between strains do exist, thus underscoring the necessity to perform developmental studies with strains that can be grown in both stages.

\section{CONCLUSIONS}

We have established a robust in vitro system from bloodstream trypanosomes that supports complete cycles of both $\mathrm{U}$ insertion and $\mathrm{U}$ deletion. Our data show that the Bf and Pf in vitro editing systems can be analyzed in parallel reactions to gain insights into potential regulatory mechanisms in the two forms. Although strain-specific sedimentation profiles are apparent, we consistently observe a sedimentation feature that distinguishes the Bf from the Pf strains used here. Namely, the peak of editing activity in Bf ILTat1.3 and 427 extracts appears to include complexes that are less dense than the peak of activity in Pf TREU667 and 427 extracts. It is possible that at least some Bf complexes are simpler in composition than equivalent Pf complexes, but further research is needed to address the basis of this difference, and additional strains must be tested to establish the generality of this observation. The Bf and Pf sedimentation fractions analyzed exhibit little if any editing activity around 40S. In procyclics, significant levels of individual editing activities (e.g., McManus et al. 2000), but only negligible full round editing activity (Correll et al. 1996), have been detected at $\sim 40$ S. $\sim 40$ S Pf complexes may seem inactive in the presence of exogenously added substrates because, in contrast to the very active $\sim 20 \mathrm{~S}$ Pf complexes, they are already assembled with endogenous pre-mRNA substrates (Pollard et al. 1992; Madison-Antenucci et al. 2002). Regardless of the molecular basis for the sedimentation profiles we observe, both strain-specific and stage-specific dif- ferences in the organization of Pf and Bf complexes may significantly influence their function.

It is intriguing that the ATP requirement for A6 editing varies, particularly for insertion, between strains. Although the potential biological significance of these differences remains to be determined, they may reflect variability in the composition of editing complexes, at least in components associated with insertion. Surprisingly, our initial attempts to further purify Bf complexes using the protocol by Rusché et al. (1997) have been quite inefficient (M. De NovaOcampo, K. Halbig, and J. Cruz-Reyes, unpubl. data). This apparent complication may reflect important biochemical differences between editing complexes in the two forms. A previously reported modulation by ATP in the Pf strain 667 occurs at the pre-mRNA cleavage step and is different for deletion and insertion (Cruz-Reyes et al. 1998a). We suspect that the ATP dependence of deletion observed in strain 667 is relatively conserved among strains whereas the ATP dependence of insertion may be more variable among strains and possibly also between stages of the same strain. Further work will clarify this question. The main goal of this work was to describe a robust Bf in vitro system for complete cycles of both insertion and deletion editing, and to show the feasibility to carry out direct and systematic comparisons with the well-established Pf system. Further studies with this system and further purified activities will facilitate gaining insights into the regulatory mechanisms of trypanosome RNA editing.

\section{MATERIALS AND METHODS}

\section{Pre-mRNA and gRNA substrates}

ATPase 6 pre-mRNA deletion and insertion were assayed at ES1 $(-3 \mathrm{U})$ and ES2 $(+3 \mathrm{U})$ using the enhanced gRNAs D33 and gA6[14]USD-3A, respectively, and 3'-end-labeled pre-mRNA substrates (Cruz-Reyes et al. 2001; Igo et al. 2002a). All transcripts were in vitro transcribed from DNA templates and gel purified as previously described (Cruz-Reyes et al. 2001).

\section{Preparation of crude mitochondrial extracts and isopycnic sedimentation analysis}

Pf T. brucei strains TREU667 and 427 (cell line 29.13) were grown in Cunningham media, and mitochondrial extracts were prepared as in Harris and Hajduk (1992), with modifications as in SollnerWebb et al. (2001). Five hundred microliters of crude mitochondrial extract $(\sim 2 \mathrm{mg}$ protein $/ \mathrm{mL})$ were applied to a $11.5-\mathrm{mL} 10 \%-$ $30 \%$ glycerol gradient in $25 \mathrm{mM}$ Tris- $\mathrm{HCl}(\mathrm{pH} 8), 10 \mathrm{mM}$ $\mathrm{Mg}(\mathrm{OAc})_{2}$ (pH 8), $10 \mathrm{mM} \mathrm{KCl}, 0.5 \mathrm{mM}$ DTT, $1 \mathrm{mM}$ EDTA, and centrifuged for $7 \mathrm{~h}$ at $40,000 \mathrm{rpm}$ in a SW40 T1 rotor at $4^{\circ} \mathrm{C}$. Approximately $0.82-\mathrm{mL}$ fractions were collected from the top of the tube in the cold room, aliquoted, and stored at $-80^{\circ} \mathrm{C}$. Dividing bloodstream slender form trypanosomes strains ILTat 1.3 and 427 (cell line 90.13 ), at $\sim 10^{9}$ cells $/ \mathrm{mL}$, were recovered by cardiac puncture from male rats (Wistar retired breeders) infected for $3 \mathrm{~d}$ after applying $\sim 0.5 \mathrm{~mL}$ intraperitoneal inoculums $\left(\sim 10^{9}\right.$ trypano- 
somes/mL; Doering et al. 1990). Heparinized infected blood was subjected to centrifugation $\left(8 \mathrm{~min}, 430 \mathrm{~g}, 4^{\circ} \mathrm{C}\right)$ and the trypanosome-containing buffy coat was recovered and passed over a DE52 column equilibrated in cold BBS (50 mM Bicine- $\mathrm{Na}+$ at $\mathrm{pH} 8,50$ $\mathrm{mM} \mathrm{NaCl}, 5 \mathrm{mM} \mathrm{KCl}$ ) with $70 \mathrm{mM}$ glucose and $0.1 \%$ bovine serum albumin. Trypanosomes were collected in the flow-through fraction free of blood cells, washed twice with BBS, and counted. Crude mitochondrial extracts and glycerol gradient fractionations were performed as above. At least two replicas of each gradient in Figures 2 and 3 were performed. The gradients in each figure ran concurrently and with the same amount of total protein. The data in these replicas was consistent and the figures are representative. We noted during this work that gradients collected from the top (rather than from the bottom) yield more reproducible and sharper distribution patterns of editing activity in different extracts and better correlation between deletion and insertion profiles for individual extracts.

To show that the growth media does not interfere with the sedimentation of the editing complexes, Pf TREU667 cells were transferred to rat blood $\left(\sim 4 \times 10^{10}\right.$ cells in $\sim 20 \mathrm{~mL}$ of heparinized whole blood) for $30 \mathrm{~min}$ before harvesting the mitochondria (data not shown). Catalase and tyroglobulin were used as $10 \mathrm{~S}$ and $19 \mathrm{~S}$ sedimentation markers, respectively, in a concurrent gradient with the extracts (Cruz-Reyes and Sollner-Webb 1996). REAP1 (Madison-Antenucci et al. 1998) was used as a 40 S marker in Western blots of gradient fractions and visualized using monoclonal antibodies kindly provided by Susan Madison-Antenucci and Steve Hajduk (University of Alabama at Birmingham).

\section{Editing and adenylylation analysis}

For $\mathrm{U}$ deletion and $\mathrm{U}$ insertion, $3^{\prime}$-end-labeled pre-mRNA ( 30 fmoles) and gRNA ( 1.25 pmoles) were preannealed (as in CruzReyes et al. 1998a) and incubated in $10 \mathrm{mM}$ MRB buffer (10 mM $\mathrm{Mg}(\mathrm{Oac})_{2}, 10 \mathrm{mM} \mathrm{KCl}, 1 \mathrm{mM}$ EDTA at $\mathrm{pH}$ 8, $25 \mathrm{mM}$ Tris- $\mathrm{HCl}$ at pH 8, 10 mM DTT, 5\% glycerol) with 1000 U/mL RNasin (Promega). Insertion reactions were supplemented with $150 \mu \mathrm{M}$ UTP. ATP was supplemented for insertion and deletion as indicated in the figures. ATP concentrations higher than $3 \mathrm{mM}$ (3.5 or $4 \mathrm{mM}$ ) have no additional effect (not shown). Twenty-microliter editing reactions, including $1 \mu \mathrm{L}$ of whole mitochondrial extract $(\sim 2-3 \mu \mathrm{g}$ protein) or $5 \mu \mathrm{L}$ of glycerol fractions $(\sim 0.5 \mu \mathrm{g}$ protein) were incubated at $26^{\circ} \mathrm{C}$ for $45 \mathrm{~min}$. Upon incubation, the RNA was deproteinized and resolved in 1-m-long 9\% acrylamide, $8 \mathrm{M}$ urea gels as previously described (Cruz-Reyes et al. 1998b). RNA treatment with calf intestinal alkaline phosphatase (CIP) once the editing reaction was completed and radiolabeling of RNA ligases by adenylylation were performed as previously described (Cruz-Reyes and Sollner-Webb 1996 and Sabatini and Hajduk 1995, respectively). Quantitation of editing products in Figures 4 and 5 were performed using a STORM PhosphorImager (Image Quant 5.0, Molecular Dynamics). Each panel in these figures corresponds to one of two replica series performed simultaneously (i.e., one experiment). The deletion and insertion series for each strain were performed using the same extract. At least two independent experiments were performed for each titration and the data shown is representative. ATP concentrations were graphed on a log scale and percent of substrate edited with error bars on a linear scale. The density of the +3 RNA, -3 RNA, and remaining input bands indicated (from two replica series) in the figures were used for these determinations.

\section{ACKNOWLEDGMENTS}

We thank Drs. Laurie K. Read, Cheng Kao, Andy C. LiWang, and Linda Guarino for comments on the manuscript and helpful discussions. We also thank Drs. Paul T. Englund and Jim C. Morris for supplying the monomorphic bloodform slender ILTat 1.3 strain and for valuable technical advise on the infection and manipulation of rats. Dr. Barbara Sollner-Webb provided the procyclic TREU667 strain. Cell lines of the 427 strain, bloodstream (90.13), and procyclic (29.13) forms were generated in Dr. George A.M. Cross's laboratory. Drs. Steve Hajduk and Susan Madison-Antenucci provided the REAP1 monoclonal antibodies. Erin RichTer and Tom Garrison in our laboratory and the personnel in the laboratory of animal research (LARR) at Texas A\&M University provided technical assistance. This work was supported by a grant from the American Heart Association, Texas affiliate, and Texas A\&M University start-up funds to J.C.-R.

The publication costs of this article were defrayed in part by payment of page charges. This article must therefore be hereby marked "advertisement" in accordance with 18 USC section 1734 solely to indicate this fact.

Received August 13, 2003; accepted March 15, 2004.

\section{REFERENCES}

Bhat, G.J., Souza, A.E., Feagin, J.E., and Stuart, K. 1992. Transcriptspecific developmental regulation of polyadenylation in Trypanosoma brucei mitochondria. Mol. Biochem. Parasitol. 52: 231-240.

Blum, B., Bakalara, N., and Simpson, L. 1990. A model for RNA editing in kinetoplastid mitochondria: 'Guide' RNA molecules transcribed from maxicircle DNA provide the edited information. Cell 60: 189-198.

Burgess, M.L.K. and Stuart, K. 2000. Sequence bias in edited kinetoplastid RNAs. RNA 6: 1492-1497.

Byrne, E.M., Connell, G.J., and Simpson, L. 1996. Guide RNA-directed uridine insertion RNA editing in vitro. EMBO J. 15: 6758-6765.

Corell, R.A., Read, L.K., Riley, G.R., Nellissery, J.K., Allen, T.E., Kable, M.L., Wachal, M.D., Seiwert, D.S., Myler, P.J., and Stuart, K.D. 1996. Complexes from Trypanosoma brucei that exhibit deletion editing and other editing-associated properties. Mol. Cell. Biol. 16: $1410-1418$.

Cruz-Reyes, J. and Sollner-Webb, B. 1996. Trypanosome U-deletional RNA editing involves gRNA-directed endonuclease cleavage, terminal U-exonuclease and RNA ligase activities. Proc. Natl. Acad. Sci. 93: 8901-8906.

Cruz-Reyes, J., Rusché, L., Piller, K., and Sollner-Webb, B. 1998a. Trypanosoma brucei RNA editing: Adenosine nucleotides inversely affect $\mathrm{U}$ deletion and $\mathrm{U}$ insertion reactions at mRNA cleavage. Mol. Cell 1: 401-409.

Cruz-Reyes, J., Rusché, L.N., and Sollner-Webb, B. 1998b. Trypanosoma brucei $\mathrm{U}$ insertion and $\mathrm{U}$ deletion activities co-purify with an enzymatic editing complex but are differentially optimized. Nucleic Acids Res. 26: 3634-3639.

Cruz-Reyes, J., Zhelonkina, A., Rusché, L., and Sollner-Webb, B. 2001. Trypanosome RNA editing: Simple guide RNA features enhance U deletion 100-fold. Mol. Cell. Biol. 21: 884-892.

Cruz-Reyes, J., Zhelonkina, A., Huang, C., and Sollner-Webb, B. 2002. Distinct functions of two RNA ligases in active Trypanosoma brucei RNA editing complexes. Mol. Cell. Biol. 22: 4652-4660. 
Doering, T.L., Raper, J., Buxbaum, L.U., Hart, G.W., and Englund, P.T. 1990. Biosynthesis of glycosyl phosphatidylinositol protein anchors. Methods 1: 288-296.

Domingo, G.J., Palazzo, S.S., Wang, B., Pannicucci, B., Salavati, R., and Stuart, K. 2003. Dyskinetoplastic Trypanosoma brucei contains functional editing complexes. Eukariot. Cell. 2: 569-577.

Gull, K. 2001. The biology of kinetoplastid parasites: Insights and challenges from genomics and post-genomics. Int. J. Parasitol. 31: $443-452$.

Harris, M.E. and Hajduk, S.L. 1992. Kinetoplastid RNA editing: In vitro formation of cytochrome b gRNA-mRNA chimeras from synthetic substrate RNAs. Cell 20: 1091-1099.

Huang, C.E., Cruz-Reyes, J., Zhelonkina, A.G., O’Hearn, S., Wirtz, E., and Sollner-Webb, B. 2001. Roles for ligases in the RNA editing complex of Trypanosoma brucei: Band IV is needed for U-deletion and RNA repair. EMBO J. 20: 4694-4703.

Igo Jr., R.P., Lawson, S.D., and Stuart, K. 2002a. RNA sequence and base pairing effects on insertion editing in Trypanosoma brucei. Mol. Cell. Biol. 22: 1567-1576.

Igo Jr., R.P., Weston, D.S., Ernst, N.L., Panigrahi, A.K., Salavati, R., and Stuart, K. 2002b. Role of uridylate-specific exoribonuclease activity in Trypanosoma brucei RNA editing. Eukaryot. Cell. 1: 112118.

Kable, M.L., Seiwert, S.D., Heidmann, S., and Stuart, K. 1996. RNA editing: A mechanism for gRNA-specified uridylate insertion into precursor mRNA. Science 273: 1189-1195.

Koslowsky, D.J. and Yahampath, G. 1997. Mitochondrial mRNA 3' cleavage/polyadenylation and RNA editing in Trypanosoma brucei are independent events. Mol. Biochem. Parasitol. 90: 81-94.

Lukes, J., Guilbride, D.L., Votypka, J., Zikova, A., Benne, R., and Englund, P.T. 2002. Kinetoplast DNA network: Evolution of an improbable structure. Eukaryot. Cell 4: 495-502.

Madison-Antenucci, S., Sabatini, R.S., Pollard, V.W., and Hajduk, S.L. 1998. Kinetoplastid RNA-editing-associated protein 1 (REAP-1): A novel editing complex protein with repetitive domains. $E M B O \mathrm{~J}$. 1: 6368-6376.

Madison-Antenucci, S., Grams, J., and Hajduk, S.L. 2002. Editing machines: The complexities of trypanosome RNA editing. Cell 108: 435-438.

McManus, M.T., Shimamura, M., Grams, J., and Hajduk, S.L. 2000. Identification of candidate mitochondrial RNA editing ligases from Trypanosoma brucei. RNA 7: 167-175.

Michelotti, E.F., Harris, M.E., Adler, B., Torri, A.F., and Hajduk, S.L. 1992. Trypanosoma brucei mitochondrial ribosomal RNA synthesis, processing and developmentally regulated expression. Mol. Biochem. Parasitol. 54: 31-42.

Militello, K.T. and Read, L.K. 1999. Coordination of kRNA editing and polyadenylation in Trypanosoma brucei mitochondria: Complete editing is not required for long poly(A) tract addition. Nucleic Acids Res. 27: 1377-1385.

Pai, R.D., Oppegard, L.M., and Connell, G.J. 2003. Sequence and structural requirements for optimal guide RNA-directed insertional editing within Leishmania tarentolae. RNA 9469-9483.

Pelletier, M. and Read, L.K. 2003. RBP16 is a multifunctional gene regulatory protein involved in editing and stabilization of specific mitochondrial mRNAs in Trypanosoma brucei. RNA 9: 457-468.

Pollard, V.W., Harris, M.E., and Hajduk, S.L. 1992. Native mRNA editing complexes from Trypanosoma brucei mitochondria. EMBO J. 11: 4429-4438.

Priest, J.W. and Hajduk, S.L. 1994. Developmental regulation of mitochondrial biogenesis in Trypanosoma brucei. J. Bioenerg. Biomembr. 2: 179-191.

Read, L.K., Stankey, K.A., Fish, W.R., Muthiani, A.M., and Stuart, K. 1994. Developmental regulation of RNA editing and polyadenylation of four life cycle stages of Trypanosoma congolense. Mol. Biochem. Parasitol. 68: 297-306.

Rusché, L.N., Cruz-Reyes, J., Piller, K.J., and Sollner-Webb, B. 1997. Purification of a functional enzymatic editing complex from Trypanosoma brucei mitochondria. EMBO J. 16: 4069-4081.

Rusché, L.N., Huang, C.E., Piller, K.J., Hemann, M., Wirtz, E., and Sollner-Webb, B. 2001. The two RNA ligases of the Trypanosoma brucei RNA editing complex: Cloning the essential band IV gene and identifying the band V gene. Mol. Cell. Biol. 21: 979-989.

Sabatini, R. and Hajduk, S.L. 1995. RNA ligase and its involvement in guide RNA/mRNA chimera formation. Evidence for a cleavageligation mechanism of Trypanosoma brucei mRNA editing. J. Biol. Chem. 270: 7233-7240.

Schnaufer, A., Panigrahi, A.K., Panicucci, B., Igo Jr., R.P., Salavati, R., and Stuart, K. 2001. An RNA ligase essential for RNA editing and survival of the bloodstream form of Trypanosoma brucei. Science 291: 2159-2162.

Schnaufer, A., Lewis Ernst, N., Palazzo, S.S., O’Rear J., Salavati, R., and Stuart, K. 2003. Separate insertion and deletion subcomplexes of the Trypanosoma brucei RNA editing complex. Mol. Cell 12: 307319.

Seiwert, S.D. and Stuart, K. 1994. RNA editing: Transfer of genetic information from gRNA to precursor mRNA in vitro. Science 266: 114-117.

Seiwert, S.D., Heidmann, S., and Stuart, K. 1996. Direct visualization of uridylate deletion in vitro suggests a mechanism for kinetoplastid RNA editing. Cell 84: 831-841.

Simpson, L., Aphasizhev, R., Gao, G., and Kang, X. 2004. Mitochondrial proteins and complexes in Leishmania and Trypanosoma involved in $\mathrm{U}$-insertion and $\mathrm{U}$-deletion RNA editing. RNA 10: 159170.

Sollner-Webb, B., Rusche, L.N., and Cruz-Reyes, J. 2001. Ribonuclease activities of trypanosome RNA editing complex directed to cleave specifically at a chosen site. Methods Enzymol. 341: 154-174.

Stuart, K. and Panigrahi, A.K. 2002. RNA editing: Complexity and complications. Mol. Microbiol. 45: 591-596.

Stuart, K., Allen, T.E., Heidmann, S., and Seiwert, S.D. 1997. RNA editing in kinetoplastid protozoa. Microbiol. Mol. Biol. Rev. 61: $105-120$.

Vickerman, K. 1985. Developmental cycles and biology of pathogenic trypanosomes. Br. Med. Bull. 41m: 105-114.

Wirtz, E., Hoek M., and Cross, G.A.M. 1998. Regulated processive transcription of chromatin by T7 RNA polymerase in Trypanosoma brucei. Nucleic Acids Res. 26: 4626-4634. 

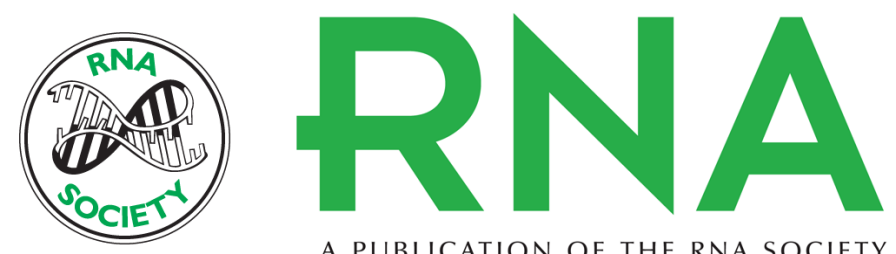

A PUBLICATION OF THE RNA SOCIETY

\section{Complete cycles of bloodstream trypanosome RNA editing in vitro}

\section{KARI HALBIG, MONICA DE NOVA-OCAMPO and JORGE CRUZ-REYES}

RNA 2004 10: 914-920

\section{References This article cites 39 articles, 16 of which can be accessed free at: http://rnajournal.cshlp.org/content/10/6/914.full.html\#ref-list-1}

\section{License}
Email Alerting Receive free email alerts when new articles cite this article - sign up in the box at the Service top right corner of the article or click here.

To subscribe to $R N A$ go to:

http://rnajournal.cshlp.org/subscriptions 